\title{
EFECTO DEL MEDIO EM-Bokashi EN EL CULTIVO DE LA MICROALGA MARINA Tetraselmis suecica K.
}

\section{EFFECT OF EM-Bokashi MEDIUM ON THE LABORATORY REARING OF THE MARINE MICRO ALGA Tetraselmis suecica $\mathrm{K}$.}

\author{
Luzmila Rodríguez $^{1,2}$, Juan Juscamaita ${ }^{2}$ y Jessie Vargas ${ }^{1}$
}

\section{Resumen}

Se estudió el efecto que ejerce el medio EM-Bokashi en el cultivo en laboratorio de la microalga marina Tetraselmis suecica K. Se aplicaron 2 medios nutritivos: medio Yashima como tratamiento control y el otro medio con componentes orgánicos provenientes de un producto fertilizante llamado EM-Bokashi. Este último fue aplicado en 3 dosis diferentes: 1:1000; 1:1500; 1:2000. Se encontró que el mejor crecimiento poblacional fue obtenido con los tratamientos con medio EM-Bokashi, y que los microorganismos probióticos contenidos en este medio en conjunto con la microalga Tetraselmis suecica presentaron efecto sinérgico al reducir la concentración de microorganismos heterótrofos presentes en el cultivo. Por lo tanto se puede afirmar que el medio EM-Bokashi es más eficiente, por promover el crecimiento del cultivo, mejorar la calidad del ambiente y presentar menor costo de producción, $98.8 \%$ menor con respecto al costo que implicaría producir la microalga con el medio Yashima.

Palabras Clave: Tetraselmis suecica, microalga, probióticos, EM-Bokashi, Yashima, crecimiento poblacional

\begin{abstract}
The effect of EM-Bokashi medium on the marine micro alga Tetraselmis suecica reared in the laboratory was studied. Two nutritive media were used: Yashima medium was used as a control treatment and the other medium had organic components coming from EM-Bokashi which is a fertilizing product. The latter was inoculated in three different doses: $1: 1000 ; 1: 1500 ; 1: 2000$. The highest population growth was obtained with EM-Bokashi and the probiotic microorganisms contained in this medium together with Tetraselmis suecica micro alga had a synergic effect in reducing the concentration of heterotrophic microorganisms present in the culture. The results showed that EM-Bokashi was more efficient than Yashima because it promoted population growth, improved environmental quality and presented less production costs, which arose to 98.8 $\%$ less than the control medium.
\end{abstract}

Key words: Tetraselmis suecica, microalgae, probiotics, EM-Bokashi, Yashima, population growth

\section{Introducción}

En los últimos años se ha mostrado un gran interés por el cultivo de microalgas de forma intensiva, debido a la necesidad de obtener alimentos vivos considerando su alto valor alimenticio, su tamaño, digestibilidad y fácil capturabilidad para la cría de larvas y estadios juveniles de moluscos crustáceos y peces (Pillay, 1997; Barnabé, 1996; Coll, 1991; Farias \& Uriarte, 2002; Brown, 2002; Hoff \& Snell, 1993; Morales \& De Velotti, 1990).

La producción de microalgas es complicada y por ello es necesario usar metodologías apropiadas y medios enriquecidos, para lograr cultivos de buena densidad y libre de contaminaciones. En los cultivos intensivos se presentan factores que desestabilizan el equilibrio del medio, produciendo enfermedades y requiriendo antibióticos para reducirlas, sin embargo el uso indiscriminado de éstos ocasiona resistencia a dichos antibióticos (Pillay, 1997; Abidi, 2003; Morales \& De Velotti, 1990).

En la década del 80 el Dr. Terúo Higa desarrolló la técnica de los Microorganismos Eficaces o Benéficos (EM, en inglés Effective Micro-organisms) para KYUSEI NATURE (ORGANIC) FARMING (Higa, 1994). Los microorganismos fueron desarrollados para realzar la calidad del suelo, producir alimentos sanos, suprimiendo a microbios inductores de enfermedades., En los últimos años el sector de la acuicultura ha mostrado interés en la aplicación de los probióticos debido a los efectos beneficiosos obtenidos por su uso, reflejado tanto en el estado de salud y tasa de crecimiento, como en la calidad del medio acuático y su papel en el control biológico de enfermedades infecciosas. EM-Bokashi es un fertilizante orgánico obtenido mediante fermentación de materia orgánica por acción de los microorganismos eficaces, los cuales confieren una propiedad probiótica al compuesto 
(Balcazar, 2002; Fuller, 1989; Reviriego et al., 2001; Verschuere et al., 2000), este fertilizante puede ser utilizado como medio nutritivo en el cultivo de microalgas, y también puede ser una alternativa al uso de antibióticos. El objetivo del presente trabajo fue evaluar los efectos y propiedades del fertilizante EMBokashi utilizado como medio nutritivo en el cultivo de la microalga marina Tetraselmis suecica con el fin de mejorar su calidad productiva en la fase inicial de su cultivo.

\section{Materiales y métodos}

El cultivo de la microalga Tetraselmis suecica se llevó a cabo en aguas de baja salinidad $(20 \%)$ sin esterilización, a temperatura de $20^{\circ} \mathrm{C}$, iluminación y aireación constante en un ambiente controlado, durante 9 días. El cultivo se realizó en el Laboratorio de Acuicultura de la Facultad de Pesquería de La Universidad Nacional Agraria La Molina (UNALM).

Se evaluaron 4 tratamientos con 3 réplicas cada uno: el tratamiento control consistió en 3 matraces con $1750 \mathrm{~mL}$ de agua de mar más una dosis de medio Yashima (1 $\mathrm{mL} / \mathrm{L}), \quad$ los otros 3 tratamientos consistieron 3 matraces cada uno con diferentes dosis del medio de naturaleza orgánica EM-Bokashi: $\mathrm{T}_{1}$ $(1: 1000,1 \mathrm{~mL} / \mathrm{L}), \mathrm{T}_{2}(1: 1500,0.7 \mathrm{~mL} / \mathrm{L}), \mathrm{T}_{3}(1: 2000$, $0.5 \mathrm{~mL} / \mathrm{L})$. A los 12 matraces se agregaron inóculos de $250 \mathrm{~mL}$ de la microalga Tetraselmis suecica con una densidad celular inicial de $90-120 \times 10^{4}$ células $/ \mathrm{mL}$.

La composición de los medios nutritivos fue la siguiente:

- Medio Yashima: $74.1 \%$ de sulfato de amonio, $7.4 \%$ de urea, $11.1 \%$ superfosfato de $\mathrm{K}, 3.7 \%$ de EDTA, 3.7\% solución de minerales y vitamina $\mathrm{B}$ (FAO, 1984).

- Medio EM-Bokashi: 50\% de salvado de trigo, 30\% de harina de soya, 18\% de cebadina, 2\% de Carbón vegetal, $10 \%$ de EM activado compuesto por: $10 \%$ de EM puro $+10 \%$ de Melaza $+80 \%$ de agua. Fórmula proporcionada por el Centro Experimental de Huachipa IZUNOME (EMRO, 2000).

La densidad celular (células/mL), fue evaluada a diario siguiendo el método del hemocitómetro, utilizando una cámara de Neubauer. La tasa específica de crecimiento poblacional (r) se calculo con la siguiente formula:

Donde:

$$
\mu=(\log \text { Nf-Log No) } /(\text { Tf-To })
$$

$\mathrm{Nf}=$ densidad celular en $\mathrm{Tf}$

No $=$ densidad celular en To.

To $=$ tiempo inicial de la fase exponencial

$\mathrm{Tf}=$ tiempo final de la fase exponencial.

Los tiempos inicial y final de la fase exponencial correspondieron respectivamente al primer valor positivo y al valor máximo de las tasas de crecimiento finito $(\Delta \mathrm{N} / \Delta \mathrm{t})$ promedio.
La concentración de microorganismos fue evaluada al inicio y final del cultivo en el laboratorio de Biotecnología y Biorremediación de la UNALM, mediante el método de recuento de viables en placa, también se determinó la concentración de microorganismos probióticos presentes en el medio EM-Bokashi siguiendo el mismo método (APHA, 1980; Granados \& Villaverde, 1998). Se estimó el costo de producción de microalgas mediante comparación de costos de medios de cultivo utilizados.

Los ensayos se hicieron por triplicado y fueron verificados estadísticamente aplicando un DCA, prueba de ANOVA y pruebas de comparación de Tukey, con $\alpha=0.05$ (Calzada, 1982) usando el programa SAS.

\section{Resultados y discusión \\ Crecimiento del cultivo.}

En forma general se pudo observar que los tratamientos con dosis de EM-Bokashi $\left(\mathrm{T}_{2}, \mathrm{~T}_{3}, \mathrm{y} \mathrm{T}_{4}\right)$ desarrollaron mejor que el $\mathrm{T}_{1}$ o control. $\mathrm{El} \mathrm{T}_{3}$ con una dosis de 1:1500 de EM-Bokashi fue el que mantuvo las más altas densidades celulares siendo a su valor mas alto $16 \times 10^{5} \mathrm{cel} / \mathrm{mL}$, seguido de $\mathrm{T}_{2} \mathrm{y} \mathrm{T}_{4}$ (Figura 1), $\mathrm{T}_{4} \mathrm{y} \mathrm{T}_{1}$ presentaron crecimientos similares.

Comparando los valores de la tasa de crecimiento obtenidos durante la fase exponencial de los cultivos, no hubo diferencias significativas entre $T_{2} \quad \mathrm{y}_{3}$ y tampoco entre $\mathrm{T}_{1} \mathrm{y} \mathrm{T}_{4}$ (Anexo 1). Los Tratamientos 2 y 3 presentaron las mayores tasas especificas de crecimiento, 0.73 días $^{-1}$ y 0.65 días $^{-1}$ respectivamente (Tabla 1).

Las tasas de crecimiento obtenidas en todos los tratamientos fueron también mayores que las estimadas de los datos de Carrera (2006) para el cultivo de Tetraselmis suecica con medio Guillard modificado, con un valor máximo de 0.20 día $^{-1}$.

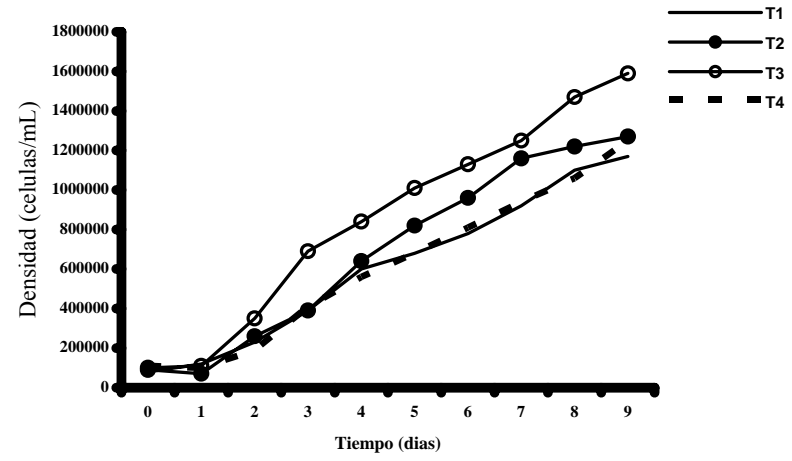

Figura 1. Curvas de crecimiento poblacional de la microalga Tetraselmis suecica $\mathrm{K}$. $\mathrm{T}_{1}$ o control con dosis de medio Yashima 1:1000; $\mathrm{T}_{2}$ con dosis de EM-Bokashi 1:1000; $\mathrm{T}_{3}$ con dosis de EM-Bokashi 1:1500; $\mathrm{T}_{4}$ con dosis de EM-Bokashi 1:2000. 
Tabla 1. Valores promedio de la tasa específica de crecimiento poblacional $(\mu)$, de la microalga Tetraselmis suecica.

\begin{tabular}{|c|c|c|c|c|}
\hline TRATAMIENTOS & $\mu\left(\right.$ días $\left.^{-1}\right)$ & R1 & R2 & R3 \\
\hline$T_{1}$ Yashima (1:1000) & $0.48^{\mathrm{b}}$ & 0.50 & 0.50 & 0.45 \\
\hline $\begin{array}{l}T_{2} \text { EM-Bokashi } \\
(1: 1000)\end{array}$ & $0.74^{\mathrm{a}}$ & 0.71 & 0.76 & 0.74 \\
\hline $\begin{array}{l}T_{3} \text { EM-Bokashi } \\
(1: 1500)\end{array}$ & $0.65^{\mathrm{a}}$ & 0.58 & 0.77 & 0.61 \\
\hline $\begin{array}{l}T_{4} \text { EM-Bokashi } \\
(1: 2000)\end{array}$ & $0.47^{\mathrm{b}}$ & 0.53 & 0.43 & 0.46 \\
\hline $\begin{array}{l}\text { Guillard Modificado } \\
(1: 1000)\end{array}$ & $0.20 *$ & & & \\
\hline
\end{tabular}

a,b: letras iguales indican que los promedios son estadísticamente semejantes a una $\mathrm{p}<0,05$.

*Estimado del mejor tratamiento de Carrera (2006).

No se conoce con exactitud el mecanismo de acción de EM-Bokashi sobre el cultivo de la microalga Tetraselmis suecica que permitiría que el $\mathrm{T}_{3}$ presente menor tasa de crecimiento y mayor densidad celular que el $\mathrm{T}_{2}$, aunque el crecimiento o desarrollo de un cultivo no puede ser basado directamente sobre la densidad celular si no sobre parámetros de crecimiento ya que en el conteo de microalgas podrían haber errores.

En la Figura 2 se observa el comportamiento de la tasa de crecimiento en función a las dosis de EMBokashi, lo que indica una relación directa, la tasa de crecimiento va incrementando a mayor dosis pero se observa también que en una mayor dosis va llegando a punto de saturación donde ya no habrá incremento, esto sugiere que los crecimientos algales óptimos no se obtienen con las mayores cantidades de fertilizante, sino con dosis equilibradas. Al igual que en las plantas superiores se busca una dosis adecuada para lograr óptimos resultados: cuando se aplica dosis en demasiada cantidad podría ocasionar un efecto tóxico, desperdiciando medio nutritivo; mientras que en dosis pequeñas no se lograrían la densidad poblacional adecuada con un buen rendimiento y quizás con poco valor nutritivo.

Determinación de las Concentraciones de Microorganismos Heterótrofos.

Se determinó la cantidad aproximada microorganismos probióticos presentes en el medio EMBokashi. Las Bacterias Aerobias Mesófilas Viables presentaron una concentración de $71 \times 10^{7} \mathrm{UFC} / \mathrm{mL}$, los cuales se adicionaron a los tratamientos en forma proporcional de acuerdo a las dosis requeridas.

En la Figura 3 se puede apreciar las concentraciones de microorganismos al inicio y final del cultivo. Al inicio todos los tratamientos, antes de aplicar dosis de medios nutritivos, presentan una concentración de microorganismos $20 \times 10^{4} \mathrm{UFC} / \mathrm{mL}$ (agua de mar no estéril e inóculo de microalgas) e inmediatamente después al añadir los medios de cultivo, $\mathrm{T}_{2}$ presentó la mayor concentración de microorganismos $\left(91 \times 10^{4} \mathrm{UFC} / \mathrm{mL}\right)$ con respecto a los otros tratamientos, al recibir la mayor dosis de EMBokashi, ya que este contiene organismos probióticos mientras que el $\mathrm{T}_{1}$ o control $\left(20 \times 10^{4}\right.$ $\mathrm{UFC} / \mathrm{mL}$ ) no recibió dosis adicional de microorganismos por parte del medio Yashima (medio inorgánico estéril).

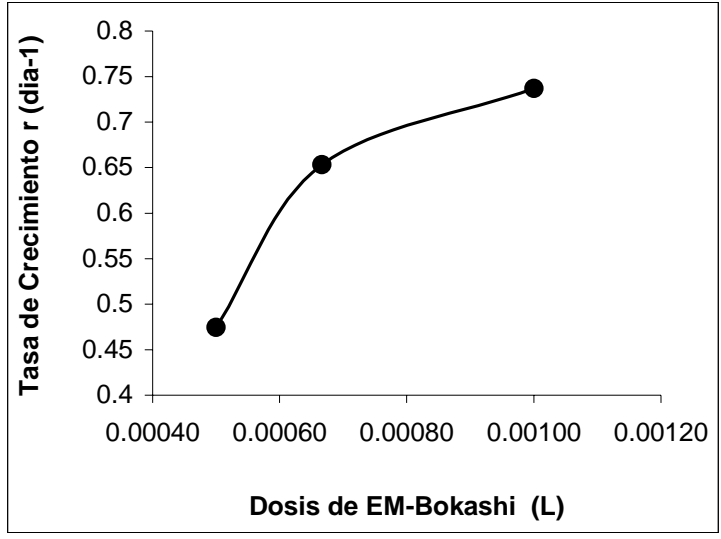

Figura $\mathbf{N}$ 2: Comportamiento de la tasa de crecimiento $\mu$ (días $^{-1}$ ) en función a las dosis de EMBokashi.

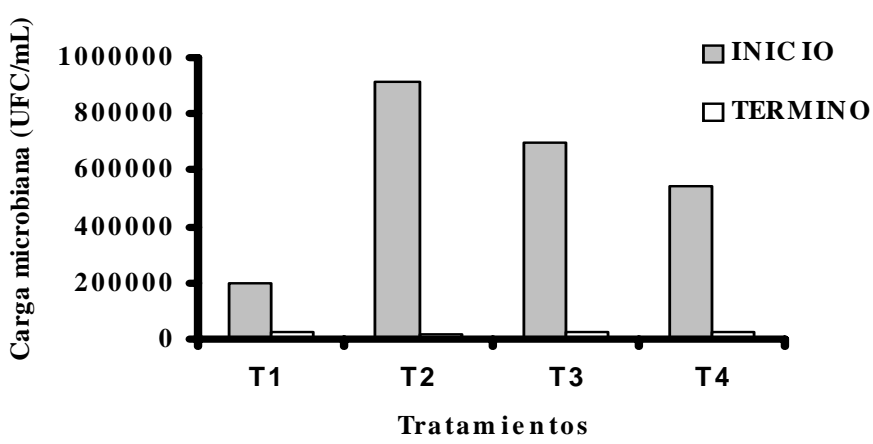

Figura 3. Concentración de la carga microbiana heterótrofa, al inicio y final del periodo de cultivo de la microalga Tetraselmis suecica $(\mathrm{UFC} / \mathrm{mL}) . \mathrm{T}_{1}$ con dosis de medio Yashima 1:1000; $\mathrm{T}_{2}$ con dosis de EMde Bokashi 1:1000; $\mathrm{T}_{3}$ con dosis de EM-Bokashi dosis 1:1500; $T_{4}$ con dosis de EM-Bokashi 1:2000.

En el recuento final $\mathrm{T}_{2}$ presentó el mayor porcentaje de reducción de microorganismos, $98.1 \%$ de su valor inicial, seguido de $\mathrm{T}_{3}, \mathrm{~T}_{4}, \mathrm{~T}_{1}(96.4 \%$, $95.1 \%, 89 \%$ respectivamente), así entonces $\mathrm{T}_{2}$ presentó la menor concentración de microorganismos (Tabla 2). En el $\mathrm{T}_{1}$ o control se observa que la microalga $T$. suecica presenta capacidad inhibitoria de bacterias patógenas puesto que no recibió dosis de microorganismos probióticos, como lo corroboró Austin et al. (1992); tomando en cuenta esto, en los tratamientos con EM-Bokashi los microorganismos 
probióticos en conjunto con la microalga $T$. suecica tuvieron un efecto sinérgico. Tabla 2. Número de colonias de microorganismos heterótrofos
presentes en el cultivo de la microalga marina Tetraselmis suecic durante su cultivo (UFC/mL).

\begin{tabular}{|c|c|c|c|c|}
\hline Tratamientos & $\begin{array}{c}T_{1} \\
\text { Yashima } \\
(1: 1000) \\
\end{array}$ & $\begin{array}{c}T_{2} \\
\text { EM-Bokashi } \\
(1: 1000) \\
\end{array}$ & $\begin{array}{c}T_{3} \\
\text { EM-Bokashi } \\
(1: 1500) \\
\end{array}$ & $\begin{array}{c}\mathrm{T}_{4} \\
\text { EM-Bokashi } \\
(1: 2000) \\
\end{array}$ \\
\hline $\begin{array}{l}\mathrm{N}^{\circ} \text { de colonias en agua } \mathrm{c} \\
\text { cultivo }+ \text { inóculo de } \\
\text { algas } \quad(\mathrm{UFC} / \mathrm{mL})\end{array}$ & 200000 & 200000 & 200000 & 200000 \\
\hline $\begin{array}{l}\mathrm{N}^{\circ} \text { de colonias en dosis } \\
\text { aplicada de medio de } \\
\text { cultivo (UFC/mL) }\end{array}$ & 0 & 710000 & 497000 & 345000 \\
\hline $\begin{array}{l}\mathrm{N}^{\circ} \text { total de colonias al } \\
\text { inicio del cultivo } \\
\text { (UFC/mL) }\end{array}$ & 200000 & 910000 & 697000 & 545000 \\
\hline $\begin{array}{l}\mathrm{N}^{\circ} \text { total de colonias al } \\
\text { final del cultivo } \\
\text { (UFC/mL) }\end{array}$ & 22000 & 17000 & 25000 & 27000 \\
\hline $\begin{array}{l}\text { \% de reducción del } \mathrm{N}^{\circ} \\
\text { de colonias } *\end{array}$ & 89.0 & 98.1 & 96.4 & 95.1 \\
\hline
\end{tabular}

* \% de disminución respecto al valor inicial del número de colonias de r tratamiento.

Los microorganismos probióticos provenientes de EM están compuesto principalmente por 3 géneros: bacterias fototróficas, bacterias acido lácticas y levaduras. Las bacterias fototróficas utilizan materia orgánica para producir sustancias útiles para los otros microorganismos; las bacterias acido lácticas producen acido láctico lo que permite un medio estéril al suprimir bacterias patógenas; las levaduras sintetizan sustancias antimicrobianas y sustancias bioactivas (hormonas, vitaminas etc.) que sirven de sustrato para las bacterias acido lácticas que componen el medio. De esta manera los microorganismos probióticos logran dar un balance a los ecosistemas microbiales al suprimir microorganismos patógenos e incrementando la actividad de microorganismos naturales, enriqueciendo la microflora (EMRO, 2000).

Es difícil mantener un cultivo de microalgas libre de bacterias, estos organismos utilizan la materia orgánica presente del cultivo ya sea células muertas de microalgas y su proliferación podría ocasionar el colapso del cultivo, al producir sustancias que inhiben el crecimiento de microalgas (Hoff \& Snell, 1993). Balcazar (2002), indica que el principal mecanismos de acción de los probióticos es la competencia de nichos, al adicionar el medio EM-Bokashi los probióticos provenientes de dicho medio entrarían en competencia con las bacterias patógenas presentes en el agua mas inoculo, inhibiendo su desarrollo y contribuyendo al equilibrio ecológico del medio.

El pH del agua de cultivo mas inoculo es ligeramente alcalino 8.2, pudo afectar a los microorganismos probióticos provenientes del medio EM-Bokashi, ya que este medio de cultivo es acido, pero no se podría asegurar que haya sido determinante en la disminución de la concentración de microorganismos puesto que $\mathrm{pH}$ fue similar entre los tratamientos con EM-Bokashi y $\mathrm{T}_{2}$ de mayor concentración inicial de microorganismos que $\mathrm{T}_{4}$ presento al final el mayor porcentaje de reducción de microorganismos, lo que sugiere interacción de los probióticos.

Tanto EM-Bokashi como la microalga podrían actuar como agente controlador de patógenos, pero las sustancias inhibidoras de la microalga no producirían tantos beneficios como los probióticos del EM-Bokashi, aunque la cuantificación final no haya sido muy diferente, EM-Bokashi es más eficiente, ya que según los resultados obtenidos promueven el crecimiento del cultivo.

Determinación de costos de producción de cultivos

Se considero un volumen referencial de 1000 L de cultivo de microalgas para determinar los costos por comparación, esto se hizo en base a cálculos hipotéticos proyectándose sobre los datos obtenidos durante el periodo de evaluación

Los tratamientos 2 y 3 presentaron los mejores resultados de los tratamientos con medio EM-Bokashi, no obstante se considero solo el tratamiento 3 al no haber diferencias significativas con respecto al tratamiento $2 \mathrm{y}$ por que requiere menor cantidad de medio de cultivo que $\mathrm{T}_{2}$ y se comparo con $\mathrm{T}_{1}$. El tratamiento 3 presentó una densidad promedio de $84 \times 10^{4} \mathrm{cel} / \mathrm{mL}$ y el tratamiento 1 o control presento una densidad de $60 \times 10^{4} \mathrm{cel} / \mathrm{mL}$, las densidades 60 $100 \times 10^{4} \mathrm{cel} / \mathrm{mL}$ son las que el laboratorio de acuicultura utiliza para el escalamiento de cultivos por estar dentro de la fase exponencial, en no mas de 4 días antes de que el cultivo empiece a envejecer.

En la tabla 3 se muestran los valores aproximados de los costos para el cultivo de microalgas. Para producir $1 \mathrm{~L}$ de microalgas se requiere de $0.0007 \mathrm{~L}$ de medio EM-Bokashi y en el caso del medio Yashima de $0.001 \mathrm{~L}$, con un costo de S/ 0.00023 y 0.01953 respectivamente, entonces el costo que implicaría producir 1000 Litros de microalgas con medio EMBokashi es S/ 0.230 mientras que con medio Yashima seria $\mathrm{S} / 19.530$, resultando en un costo de producción 98.8\% menor con medio EM-Bokashi comparado con medio Yashima.

\section{Conclusiones}

- En los cultivos de microalgas, los tratamientos con medio EM-Bokashi favorecieron mayores tasas específicas de crecimiento poblacional $(\mu)$ comparado con el tratamiento control.

- Los tratamientos 2 y 3 con medio EM-Bokashi presentaron mayores valores de tasa específica de 
crecimiento $\left(\mu=0.74\right.$ y $0.65 \mathrm{día}^{-1}$, respectivamente), aunque no hubo diferencias significativas entre ellas

- Los microorganismos probióticos del medio EMBokashi mostraron un efecto sinérgico con la microalga Tetraselmis suecica, al reducir la concentración de microorganismos heterótrofos presentes en el cultivo, obteniendo mayor reducción a mayor dosis aplicada.

- El medio EM-Bokashi presentó mayor eficiencia que el medio Yashima, por promover el crecimiento del cultivo, mejorar la calidad del ambiente al reducir la concentración de microorganismos y por lograr una producción con un costo $98.8 \%$.

Tabla 3. Comparación de costos para obtener $1000 \mathrm{~L}$ de cultivo de la microalga Tetraselmis suecica.

\begin{tabular}{|c|c|c|}
\hline Medio de cultivo & Yashima & $\begin{array}{c}\text { EM- } \\
\text { Bokashi }\end{array}$ \\
\hline $\begin{array}{l}\text { Volumen Referencial de cultivo } \\
\text { de microalga }(L)\end{array}$ & 1000 & 1000 \\
\hline $\begin{array}{l}\text { Densidad de microalgas en } \\
\text { Cosecha }(\mathrm{cel} / \mathrm{mL})\end{array}$ & $60 \times 10^{4}$ & $84 \times 10^{4}$ \\
\hline $\begin{array}{l}\text { Costo de medio de cultivo } \\
\text { - } 1 \text { Litro (S/) }\end{array}$ & 19.53 & 0.33 \\
\hline $\begin{array}{l}\text { Medio de cultivo utilizado para } \\
\text { producir } \\
1 \text { L de microalgas }(L)\end{array}$ & 0.001 & 0.0007 \\
\hline $\begin{array}{l}\text { Medio de cultivo utilizado para } \\
\text { obtener } \\
1000 \text { L de microalgas }(L)\end{array}$ & 1.0 & 0.7 \\
\hline $\begin{array}{l}\text { Costo para producir } 1 \mathrm{~L} \text { de } \\
\text { microalgas } \\
(\mathrm{S} /)\end{array}$ & 0.01953 & 0.00023 \\
\hline $\begin{array}{l}\text { Costo para producir } 1000 \mathrm{~L} \text { de } \\
\text { microalgas) }\end{array}$ & 19.530 & 0.230 \\
\hline
\end{tabular}

\section{Agradecimientos}

Este estudio se llevó a cabo gracias al apoyo financiero del Laboratorio de Biorremediación del Departamento de Biología de la Facultad de Ciencias y el Laboratorio de Acuicultura de la Facultad de Pesquería de la Universidad Nacional Agraria La Molina, Lima - Perú.

\section{Literatura citada}

Abidi R. 2003. Use of Probiotics in Larval rearing of New Candidate Species. National Bureau of Fish Genetic Resources Telibagh, U. P. India. 8 (2): 15-16.

AMERICAN PUBLIC HEALTH ASSOCIATION (APHA), AMERICAN WATER WORKS ASSOCIATION (AWWA), WATER POLLUTION CONTROL FEDERATION (WPCF). 1980. Standard Methods For the examination of Water and Seawater. $15^{\circ}$ Edición. Editorial BOARD. Washington-USA.

Austin B., Baudet E. \& Stobie M. 1992. Inhibition of Bacterial Fish Pathogens by Tetraselmis suecica. Journal of fishes Diseases. 15: 55-61.

Balcazar J.L. 2002. Uso de Probióticos en acuicultura: Aspectos Generales. I Congreso Iberoamericano Virtual de Acuicultura. CIVA 2002. Facultad de Acuicultura, Universidad de Machala. Ecuador. : 877-881.
Barnabé G. 1996. Bases Biológicas y Ecológicas de la Acuicultura. Editorial ACRIBIA S.A. España.

Brown M. 2002. Nutritional Value and Use of Microalgae in Aquaculture. In: Cruz-Suárez L., Ricque-Marie D., Tapia-Salazar M., Gaxiola-Cortés M. \& Simoes N. (Eds). Avances en Nutrición Acuícola VI. Memorias del VI Simposium Internacional de Nutrición Acuícola. 3 al 6 de Septiembre del 2002. Cancún, Quintana Roo. México. : 281-292.

Calzada J. 1982. Métodos Estadísticos para la Investigación. Editorial Milagritos S. A. Lima, Perú.

Carrera J. 2006. Efecto de diferentes concentraciones de productos zeolíticos sobre el cultivo de las microalgas marinas Tetraselmis suecica y Chaetoceros sp. Tesis (Ing. Pesquero y Acuicultor). Universidad Nacional Federico Villarreal, Facultad de Oceanografía y acuicultura. Lima, Perú.

Coll J. 1991. Acuicultura Marina Animal. Ediciones Mundi - Prensa. Tercera Edición. España.

EFFICIENT MICROORGANISMS RESEARCH ORGANIZATION (EMRO). 2000. Disponible en http://www.chujosl.com/html/tecno.html. Consultado el 27 de Abril del 2005.

Farías A. \& Uriarte I. 2002. Nutrición en Larvicultura de Pectínidos: Relevancia de Proteínas y Lípidos. In: CruzSuárez L.E., Ricque-Marie D., Tapia-Salazar M., Gaxiola-Cortés M. G. \& Simoes N. (Eds.). Avances en Nutrición Acuícola VI. Memorias del VI Simposium internacional de nutrición acuícola. 3 al 6 de Septiembre del 2002. Cancún, Quintana Roo, México.

Fuller R. 1989. Probiotics in man and animals. Journal Applied Bacteriology. 66: 365-378.

FUNDACIÓN DE ASESORIAS PARA EL SECTOR RURAL (FUNDASES).1988. Disponible en http://www.fundases.com/p/quienes somos.html. Consultado el 13 de Marzo del 2005

Granados R. \& Villaverde M. 1998. Ciencias de la Salud. Microbiología. Bacteriología, Medios de cultivo y Pruebas Bioquímicas, Micología General, Parasitología General. Editorial Paraninfo. España .

Higa T. 1994. Kyusei nature farming. Department of Horticulture. College of Agriculture University of the Ryukyus. Disponible en http://www.spiritwheel.com/thnfarm.htm. Consultado el 25 de Febrero del 2005.

Hoff F. \& Snell T. 1993 . Plankton Culture Manual. Published Florida Aqua Farms. Ino. Florida.

Morales V.V. \& De Velotti A. 1990. Fitoplancton. PRADEPESCA. UNION EUROPEA Y OLDEPESCA Cartilla 2. : 1-21.

Pillay T. 1997.Acuicultura. Principios y Prácticas. Editorial LIMUSA. S.A. Primera Edición. México.

Reviriego C., Fernández A., Langa S., Martín R., Haza A.I., Morales P. \& Rodríguez J.M. 2001. Probióticos y Acuicultura. Pescados y Productos de la Pesca. Alimentación. Equipos y Tecnología. : 73-76.

Verschuere L., Rombaut G., Sorgeloos P. \& Verstraete W. 2000. Probiotic Bacteria as Biological Control Agents in Aquaculture. Microbiology and Molecular Biology. Reviews. 64 (4): 655-671. 
Diciembre 2007

\section{ANEXO 1}

Análisis estadístico para las tasas de crecimiento de la microalga Tetraselmis suecica: DCA, a) prueba de ANOVA y b) prueba de comparación de Tukey para un nivel de significación $(\alpha)$ de 0.05 .

a) Prueba de ANOVA

Tasa especifica de crecimiento $(\mu)$

\begin{tabular}{|l|r|c|c|c|l|}
\hline Fuente & GL & Suma de cuad. & Cuad. Medio & Valor F & Pr > F \\
\hline Tratamientos & 3 & 0.15140000 & 0.05046667 & 13.89 & 0.0015 \\
\hline Error & 8 & 0.02906667 & 0.00363333 & & \\
\hline Total & 11 & 0.18046667 & & & \\
\hline
\end{tabular}

\section{b) Prueba de comparacion de Tukey}

Tasa Específica de crecimiento $(\mu)$

- $\quad$ Alfa $(\alpha)$

0.05

- Grados de Libertad del Error (GL)

8

- $\quad$ Amplitud Estudiantizada Significativa de Tukey 4.52880 (4.53)

Letras iguales indican que los promedios son estadísticamente semejantes a una $\mathrm{p}<0.05$.

$\begin{array}{cccc}\text { Agrupamiento } & \text { Media } & \text { N } & \text { Tra } \\ \text { A } & 0.73667 & 3 & 2 \\ \text { A } & 0.65333 & 3 & 3 \\ \text { B } & 0.48333 & 3 & 1 \\ \text { B } & 0.47333 & 3 & 4\end{array}$

${ }^{1}$ Laboratorio de Acuicultura, Facultad de Pesquería, Universidad Nacional Agraria La Molina, Lima Perú / jesvargas@1amolina.edu.pe

${ }^{2}$ Laboratorio de Bioremediación, Facultad de Ciencias, Universidad Nacional Agraria La Molina, Lima Perú / jjm@1amolina.edu..pe, mila_zrod@yahoo.es 